\title{
e-LOCK: PENCEGAH PENGGUNAAN KENDARAAN BERMOTOR OLEH ANAK DI BAWAH UMUR BERBASIS IOT
}

\author{
Vina Fitriana1, Siti Kholifah², Firman Aprianto $^{3}$, R. W.Tri Hartono ${ }^{4}$ \\ 1,2,3 Jurusan Teknik Elektro, Politeknik Negeri Bandung, Bandung 40012 \\ ${ }^{1}$ E-mail : vina.fitriana.tkom18@polban.ac.id \\ ${ }^{2}$ E-mail : siti.kholifah.tkom18@polban.ac.id \\ ${ }^{3}$ E-mail : firman.aprianto.tkom19@polban.ac.id \\ ${ }^{4}$ Staf Pengajar Jurusan Teknik Elektro, Politeknik Negeri Bandung, Bandung 40012 \\ E-mail : tri.hartono@polban.ac.id
}

\begin{abstract}
ABSTRAK
Kasus kecelakaan kendaraan bermotor yang disebabkan oleh anak di bawah umur semakin meningkat. Hal ini disebabkan oleh masyarakat yang kurang peduli terhadap permasalahan ini dan memberikan ijin kepada pihak yang belum mencapai usia yang dipersyaratkan untuk mengendarai kendaraan bermotor. Dalam mengatasi hal tersebut dibutuhkan pengamanan khusus agar anak di bawah umur tidak dapat menggunakan kendaraan bermotor. Pada penelitian ini telah direalisasikan sebuah sistem keamanan berbasis elektronik (e-Lock) yang dapat membatasi akses penggunaan kendaraan bermotor tersebut. Sistem dilengkapi dengan modul RFID reader yang dapat membaca ID KTP pemilik kendaraan bermotor untuk mengaktifkan kunci kontak, mikrokontroler ATmega2560 yang berfungsi untuk mengaktifkan relay sebagai saklar ON/OFF pada jalur catu daya, serta dilengkapi dengan modul GSM dan modul GPS yang dapat mengirimkan peringatan ataupun data lokasi dari kendaraan bermotor melalui smartphone. Pengujian dilakukan sebanyak 6 kali untuk 3 buah sampel E-KTP. Prototipe $e$-Lock menunjukan unjuk kerja yang baik terhadap pembacaan ID E-KTP dan pengaktifan relay dengan jarak baca efektif sejauh 2,5 cm. Pengujian terhadap GPS Tracking juga dapat menampilkan lokasi real-time dari kendaraan bermotor, sehingga dapat disimpulkan bahwa realisasi alat sesuai dengan spesifikasi yang dirancang.
\end{abstract}

\section{Kata Kunci}

Kendaraan bermotor, E-KTP, Mikrokontroler ATmega2560, RFID reader, GPS Tracking

\section{PENDAHULUAN}

Tingginya angka kecelakaan akibat penggunaan kendaraan bermotor oleh anak di bawah umur menunjukkan kurangnya pengawasan orangtua dalam memberikan akses kendaraan bermotor kepada anakanak. Dalam rentang 5 tahun setidaknya sekitar 16\% dari 875.000 korban kecelakaan, berasal dari kalangan anak-anak.

Syarat seseorang untuk mengendarai kendaraan bermotor adalah dengan memiliki Surat Ijin Mengemudi (SIM). Pengajuan SIM dipersyaratkan berdasarkan UU No.23 Tahun 2006 pasal 63 "Penduduk Warga Negara Indonesia dan Orang Asing yang memiliki Izin Tinggal Tetap yang telah berumur 17 (tujuh belas) tahun atau telah kawin atau pernah kawin wajib memiliki KTP”. Akan tetapi, banyak masyarakat yang kurang peduli terhadap permasalahan ini dengan memberikan ijin kepada anaknya yang belum mencapai usia yang dipersyaratkan sehingga angka kecelakaan lalu lintas semakin tinggi. Untuk mengatasi hal tersebut dibutuhkan pengamanan khusus agar anak di bawah umur tidak dapat menggunakan kendaraan bermotor, hal ini bertujuan untuk mengurangi angka kecelakaan lalu lintas yang diakibatkan oleh pengendara di bawah umur.
Menanggapi uraian kasus di atas, telah banyak dikembangkan alat untuk membatasi akses pada kendaraan bermotor oleh yang tidak berhak dengan teknologi Radio Frequency Identification (RFID) dengan memanfaatkan RFID dari E-KTP pengguna. Solusi alat keamanan kendaraan bermotor yang telah dikembangkan diantaranya : 1. Sistem Pengaman Motor Menggunakan Smartcard [1], 2. Implementasi RFID Sebagai Pengaman Pada Kendaraan bermotor Untuk Mengurangi Tindak Pencurian [2], 3. Pemanfaatan EKTP untuk Pengaktifan Kendaraan Bermotor berbasis Arduino UNO [3]

Solusi-solusi di atas tentu memiliki kelebihan dan kekurangannya masing-masing. Dari hasil studi literatur sebelumnya dapat diketahui permasalahan yang belum dapat diatasi, sehingga perlu ditambahkan beberapa unjuk kerja agar alat tersebut optimal. Sistem e-Lock berbeda dengan pendahulunya, e-Lock akan fokus pada fitur tambahan berupa pemanfaatan E-KTP yang dijadikan alat akses untuk menghidupkan mesin kendaraan bermotor sebagai pengganti kunci konvensional, kemudian dilengkapi dengan GPS yang dapat terintegrasi dengan Smartphone. Unjuk kerja $e$ Lock ini diharapkan dapat membantu orangtua dan polisi lalu lintas dalam membatasi anak di bawah umur atau yang belum memiliki E-KTP untuk menggunakan kendaraan bermotor dan tentu saja diharapkan dapat 
membantu pihak kepolisian untuk mengurangi tindak kejahatan pencurian kendaraan bermotor.

\section{METODOLOGI PENELITIAN}

\subsection{Persiapan Realiasi Perangkat Keras}

Pada tahapan persiapan seluruh teori-teori dasar mengenai pembuatan alat dipelajari, kemudian dilanjutkan ke tahap perancangan. Tahapan perancangan meliputi pembuatan bagan alur dari skema sistem, kemudian dilanjutkan dengan pemilihan komponen alat yang akan digunakan. Sistem yang dirancang akan terdiri atas hardware dan software. Perancangan bagian hardware terdiri atas RFID sebagai pembaca E-KTP untuk mengaktifkan dan mematikan kendaraan bermotor serta GPS dan SIM800L sebagai GPS tracking yang mengirimkan data lokasi kendaraan yang dapat diakses melalui smartphone.

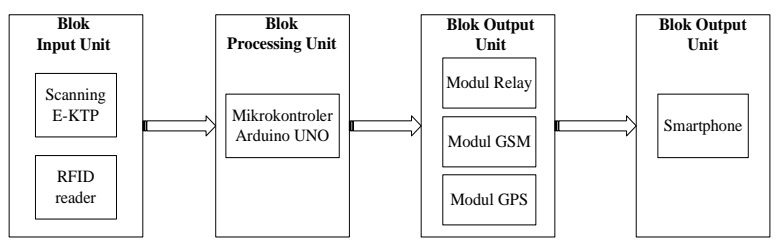

Gambar 1. Blok Diagram Sistem e-Lock

Berdasarkan blok digram pada Gambar 1 terdapat gambaran dari Sistem e-Lock yang terbagi menjadi 3 blok utama, yaitu blok Input Unit, blok Processing Unit, dan blok Output Unit. Masing-masing blok memiliki bagian- bagian yang berbeda seperti:

1. Bagian input unit berupa ID E-KTP yang telah didaftarkan pada sistem dan perangkat modul RFID. RFID akan bertindak sebagai sensor dari ID E-KTP yang di-scan.

2. Bagian processing unit berupa mikrokontroler Arduino ATmega 2650 yang akan bertindak sebagai pengolah data. Data yang telah diterima oleh perangkat modul RFID akan dikirim ke dalam mikrokontroler dan diproses, sehingga menghasilkan perintah untuk mengontrol switch elektrik, yaitu relay.

3. Bagian output unit terdapat Modul relay yang akan menyambungkan atau memutuskan listrik pada sistem kelistrikan kendaraan bermotor. Kemudian modul GSM dan GPS berfungsi untuk mengirim lokasi ke Smartphone.

\subsection{Algoritma yang Digunakan}
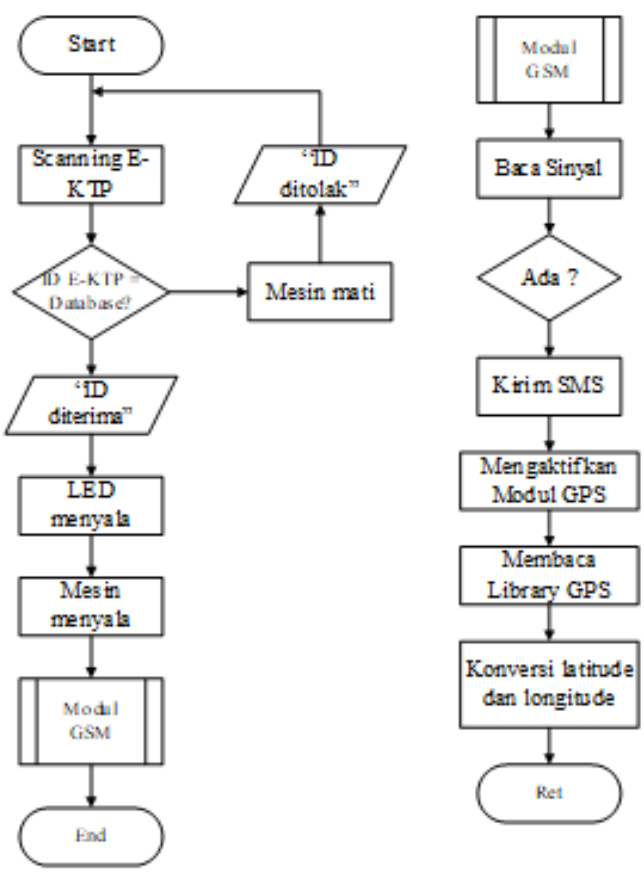

Gambar 2. Diagram Alir Sistem $e$-Lock

Pada Gambar 2 menjelaskan diagram alir dari Sistem $e$ Lock, Sistem akan melakukan scaning E-KTP pada RFID reader dan mengkonfirmasi datanya, apabila ID yang dibaca sesuai dengan ID yang ada pada program maka sistem akan menyalakan relay untuk menghidupkan kendaraan bermotor, sebaliknya apabila ID tidak sesuai maka relay untuk mesin akan $O F F$ atau mesin mati dan menyalakan alarm. Indikator dari kedua kondisi tersebut adalah munculnya notifikasi pada LCD dan hidup atau tidaknya lampu sebagai tanda kontak pada alat. Setelah mesin dihidupkan, sistem akan mengaktifkan modul GPS dan GSM dan membaca library GPS, lalu mengkonversi keberadaan dari kendaraan bermotor dan mengirimkannya ke smartphone dan akan selalu di-update pada aplikasi apabila lokasi berubah.

\subsection{Parameter Pengujian}

Pengujian dilakukan untuk memastikan dan meninjau apakah alat yang sudah dibuat memenuhi spesfikasi dari target yang diharapkan, parameter yang akan diuji dari keseluruhan sistem e-Lock adalah:

1. Pengujian terhadap kesesuaian data yang dibaca oleh modul RFID, dimana sebelumnya telah di daftarkan 3 buah ID ke dalam program, kemudian sistem akan memeriksa kesesuain data dengan program. 


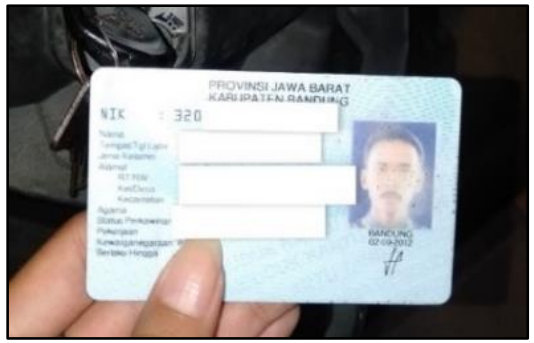

Gambar 3. Pengujian E-KTP

2. Pengujian terhadap jarak pembacaan dari RFID reader terhadap E-KTP. Jarak yang akan diuji adalah dari $1 \mathrm{~cm}-3 \mathrm{~cm}$.

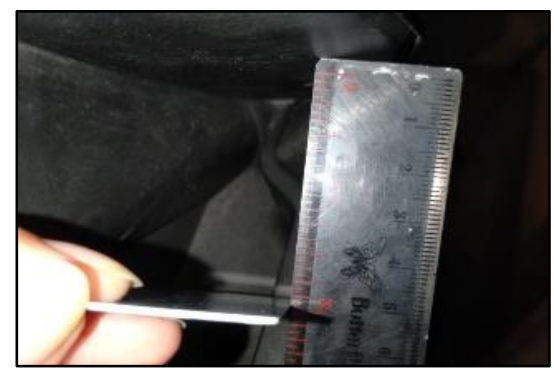

Gambar 4. Pengujian Jarak Pembacaan RFID

3. Pengujian terhadap relay pada output berupa 2 buah motor DC, 1 buah Buzzer dan 1 buah Lampu. Jika data yang diujikan berbeda, maka mesin kendaraan bermotor tidak akan aktif dan Buzzer akan menyala sebagai tanda bahwa E-KTP yang di-scan memiliki data yang tidak sesuai. Pengujian pada sistem GPS berupa tingkat akurasi informasi yang diberikan terhadap keadaan yang sebenarnya.

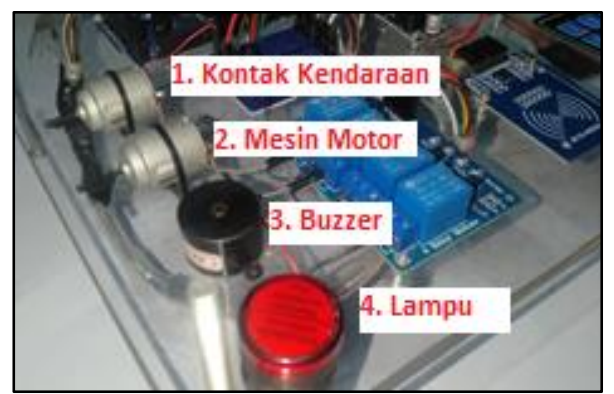

Gambar 5. Pengujian Relay

\section{HASIL DAN PEMBAHASAN}

\subsection{Realisasi Perangkat Keras}

Hasil yang didapatkan adalah sebuah prototipe sistem $e$ Lock yang merupakan sebuah alat untuk membatasi akses penggunaan kendaraan bermotor dengan menggunakan teknologi RFID. Sistem akan membaca ID E-KTP dari pengguna kendaraan bermotor yang sah dan terdaftar dalam program. Hal ini akan mengatasi penyalahgunaan penggunaan kendaraan bermotor oleh seseorang yang belum berhak atau di bawah umur. Pada Gambar 6. ditunjukkan skema rangkaian dari sistem yang sudah terintegrasi.

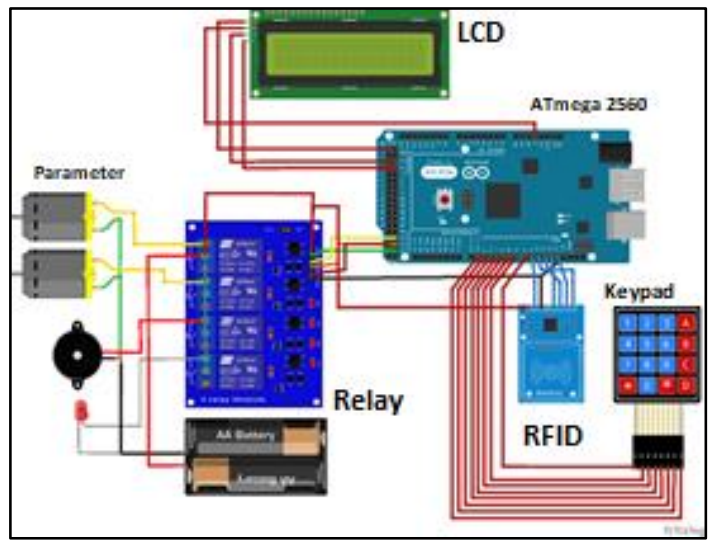

Gambar 6. Skema Rangkaian Terintegrasi

Tampilan fisik prototipe e-Lock yang telah sesuai dengan perancangan dapat dilihat pada Gambar 7, dimana prototipe terdiri atas Mikrokontroler, RFID reader, motor DC, lampu, buzzer dan modul relay 4 kanal. Masing-masing kanal berfungsi sebagai parameter yang mewakili bagian-bagian dari kendaraan bermotor seperti kontak mesin motor, klakson, dan lampu indikator. Alat ini diberi daya oleh power supply sebesar 12 volt.

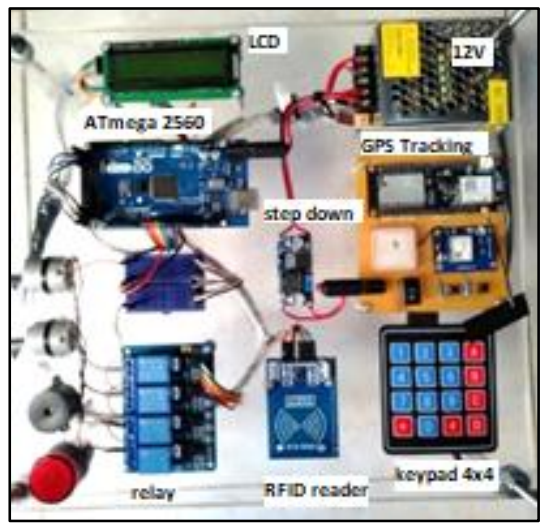

Gambar 7. Tampilan fisik Prototipe $e$-Lock

\subsection{Hasil Pengujian}

Pengujian dilakukan terhadap kemampuan pembacaan dan pengiriman data oleh modul RFID, dimana sebelumnya telah didaftarkan 3 buah ID ke dalam program. Sistem akan memeriksa kesesuaian data hasil pembacaan dari RFID dengan program data terdaftar. Pengujian juga dilakukan terhadap jarak maksimum pembacaan dari RFID reader terhadap E-KTP. Jarak yang akan diuji beragam disesuaikan dengan spesifikasi RFID yang nanti akan digunakan. Selanjutnya, dilakukan pengujian terhadap Relay pada output berupa LED, Buzzer dan GPS sesuai dengan data input yang 
dibaca oleh sensor. Dari beberapa pengujian di atas didapatkan hasil sebagai berikut :

Tabel 1. Pengujian Pembacaan ID E-KTP

\begin{tabular}{|c|c|c|c|c|}
\hline No. & $\begin{array}{c}\text { Nama } \\
\text { KTP }\end{array}$ & ID E-KTP & $\begin{array}{c}\text { Render } \\
\text { MFRC- } \\
\mathbf{5 2 2}\end{array}$ & $\begin{array}{c}\text { Sistem } \\
\text { Registrasi }\end{array}$ \\
\hline 1. & $\mathrm{KTP}_{1}$ & $\begin{array}{c}20,149, \\
43,43,129\end{array}$ & Terdaftar & Terbaca \\
\hline 2. & $\mathrm{KTP}_{2}$ & $\begin{array}{c}57805 \mathrm{D} \\
62\end{array}$ & Terdaftar & Terbaca \\
\hline 3. & $\mathrm{KTP}_{3}$ & $\begin{array}{c}8945 \mathrm{BD} \\
\mathrm{C} 2\end{array}$ & $\begin{array}{c}\text { Tidak } \\
\text { Terdaftar }\end{array}$ & Tidak terbaca \\
\hline
\end{tabular}

Pada Tabel 1 terlihat hasil dari pengujian pembacaan EKTP oleh RFID reader. Alat e-Lock telah berhasil mengidentifikasi E-KTP yang terdaftar dan yang belum terdaftar. Apabila E-KTP telah terdaftar pada program maka akan mengaktifkan Sistem e-Lock. Apabila EKTP belum terdaftar maka akan otomatis mengaktifkan Alarm atau Buzzer sebagai fitur pengamanan kendaraan bermotor.

Tabel 2. Pengujian Jarak Baca Maksimum ID E-KTP

\begin{tabular}{|c|c|c|c|c|c|}
\hline \multicolumn{2}{|c|}{ Percobaan Card } & \multicolumn{2}{|c|}{ Percobaan E-KTP } & \multicolumn{2}{|c|}{ Percobaan Tag } \\
\hline $\begin{array}{c}\text { Jarak } \\
(\mathbf{c m})\end{array}$ & Keterangan & $\begin{array}{c}\text { Jarak } \\
(\mathbf{c m})\end{array}$ & Keterangan & $\begin{array}{c}\text { Jarak } \\
(\mathrm{cm})\end{array}$ & keterangan \\
\hline 1,2 & Terbaca & 1,2 & Terbaca & 1,2 & Terbaca \\
\hline 1,4 & Terbaca & 1,4 & Terbaca & 1,4 & Terbaca \\
\hline 1,8 & Terbaca & 1,8 & Terbaca & 1,8 & $\begin{array}{c}\text { Tidak } \\
\text { Terbaca }\end{array}$ \\
\hline 2 & Terbaca & 2 & Terbaca & 2 & $\begin{array}{c}\text { Tidak } \\
\text { Terbaca } \\
\end{array}$ \\
\hline 2,5 & Terbaca & 2,5 & Terbaca & 2,5 & $\begin{array}{c}\text { Tidak } \\
\text { terbaca }\end{array}$ \\
\hline 3 & $\begin{array}{c}\text { Tidak } \\
\text { Terbaca }\end{array}$ & 3 & $\begin{array}{c}\text { Tidak } \\
\text { Terbaca } \\
\end{array}$ & 3 & Terbaca \\
\hline
\end{tabular}

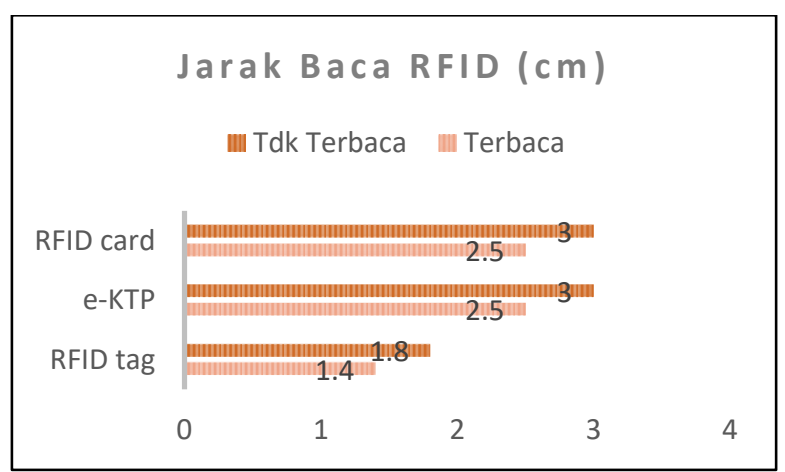

Gambar 8. Grafik Uji Jarak Pembacaan

Dari hasil pengujian pada Tabel 2 didapatkan grafik seperti pada Gambar 8 dimana jarak maksimum dari pembacaan RFID Card dan E-KTP sejauh $2,5 \mathrm{~cm}$. Sedangkan untuk RFID Tag memiliki jarak baca maksimum sejauh $1,8 \mathrm{~cm}$ pada posisi sejajar antara tag dan reader. Pembacaan kode tidak dapat terjadi jika posisi keduanya saling tegak lurus. Melalui hasil pengujian ini dapat dikatakan bahwa RFID telah bekerja sesuai dengan spesifikasi yang ditawarkan.
Tabel 3. Pengujian Sistem Relay

\begin{tabular}{|c|c|c|c|c|c|c|c|c|}
\hline \multirow{4}{*}{ KTP } & \multicolumn{4}{|c|}{ Pembacaan } & \multicolumn{3}{c|}{$\begin{array}{c}\text { Status } \\
\text { Relay }\end{array}$} \\
\cline { 2 - 10 } & $\begin{array}{c}\text { Sistem } \\
\text { Kelistrika } \\
\mathbf{n}\end{array}$ & $\begin{array}{c}\text { Mesi } \\
\text { Moto } \\
\mathbf{r}\end{array}$ & $\begin{array}{c}\text { Alar } \\
\mathbf{m}\end{array}$ & $\begin{array}{c}\text { Lamp } \\
\mathbf{u}\end{array}$ & $\mathbf{1}$ & $\mathbf{2}$ & $\mathbf{3}$ & $\mathbf{4}$ \\
\hline KTP1 & $\sqrt{ }$ & $\sqrt{ }$ & $\mathrm{x}$ & $\sqrt{ }$ & 1 & 1 & 0 & 1 \\
\hline KTP2 & $\sqrt{ }$ & $\sqrt{ }$ & & $\sqrt{ }$ & 1 & 1 & 0 & 1 \\
\hline KTP3 & $\mathrm{x}$ & $\mathrm{x}$ & $\sqrt{ }$ & $\mathrm{x}$ & 0 & 0 & 1 & 0 \\
\hline
\end{tabular}

Keterangan :

1. $\mathrm{KTP}_{1}:$ Sistem kelistrikan, mesin motror, dan lampu $O N$, alarm $O F F$.

2. $\mathrm{KTP}_{2}:$ Sistem kelistrikan, mesin motror, dan lampu $O N$, alarm $O F F$

3. $\mathrm{KTP}_{3}$ : Sistem kelistrikan, mesin motror, dan lampu OFF, alarm $O N$

Pada Tabel 3 terdapat hasil pengujian sistem relay dilakukan untuk memastikan relay dapat bekerja dengan baik. Relay yang digunakan adalah relay 5V. Saat diberi input, relay dapat bekerja dengan baik atau dapat menghidupkan dan mematikan sistem kelistrikan pada kunci kontak. Relay dihubungkan dengan kontak sepeda motor dan sistem RFID, apabila kode ID-KTP yang dibaca sesuai dengan kode yang telah diinputkan dalam program maka akan mengaktifkan ke-4 parameter.

Selanjutnya pengujian terhadap GPS Tracking dilakukan dengan mengkonfigurasi pemrograman pada mikrokontroler ESP32 TTGO-Call hingga sistem dapat mengirimkan lokasi kendaraan secara real-time dalam aplikasi Blynk. Hal ini akan memudahkan pengguna dalam melacak lokasi kendaraannya sehingga pengawasan dapat dilakukan dengan menggunakan smartphone. Berikut adalah hasil pelacakan yang ditampilkan dalam aplikasi $e$-Lock : 

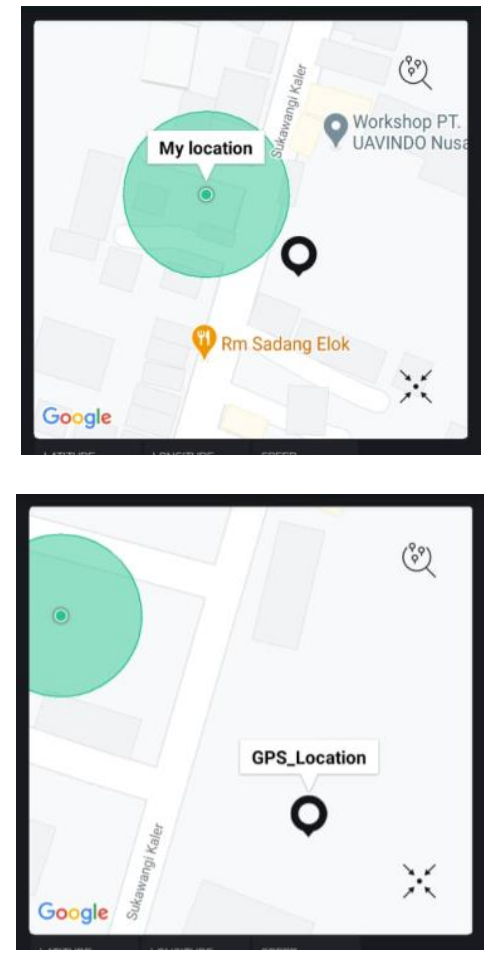

Gambar 9. Tampilan Lokasi real-time

Gambar 9 merupakan hasil dari pembacaan modul GPS secara real-time pada aplikasi Blynk. dimana terdapat 2 buah pin lokasi yang ditampilkan yaitu lokasi dari Smartphone (My location) dan lokasi dari prototipe atau kendaran bermotor (GPS_Location). Dapat dilihat dari gambar tersebut menunjukkan lokasi dengan keterangan koordinat latitude yaitu -6.9447015 dan longitude 107.5325465. Data tersebut sesuai dengan data acuan yang ambil dari Google Maps seperti yang ditunjukan pada Gambar 10.

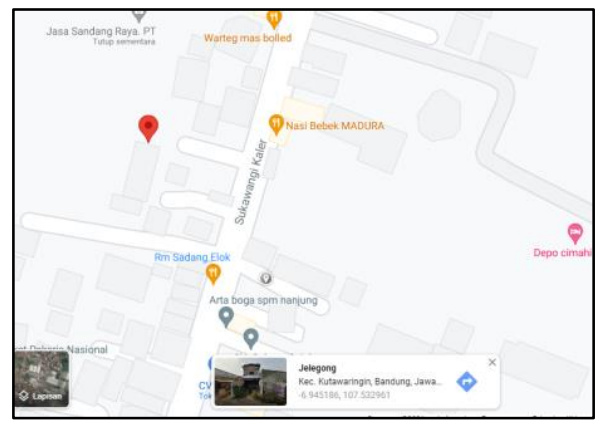

Gambar 10. Tampilan Data Acuan Google Maps

\section{KESIMPULAN}

Berdasarkan hasil pengujian dan pengamatan yang dilakukan terhadap prototipe $e$-Lock, dapat disimpulkan bahwa secara keseluruhan prototipe e-Lock ini sudah berfungsi dengan baik juga sesuai dengan perancangan yang telah dibuat. Pembacaan E-KTP oleh RFID reader sesuai dengan program, yaitu dapat membedakan ID yang telah terdaftar dan belum terdaftar. Berdasarkan hasil pengujian jarak baca efektif RFID reader sejauh
2,5 cm. Bagian GPS Tracking juga telah berhasil menujukan data real-time yang dapat di akses menggunakan aplikasi Blynk pada smartphone pengguna.

\section{UCAPAN TERIMA KASIH}

Terima kasih kepada segenap Pimpinan Politeknik Negeri Bandung karena dengan perolehan pendanaan yang didanai dari DIPA POLBAN, e-Lock ini dapat direalisasikan sesuai dengan waktu yang ditentukan.

\section{DAFTAR PUSTAKA}

[1] Efrianto, R. and I. Fahruzi, "Sistem Pengaman Motor Menggunakan Smartcard Politeknik Negeri Batam," Jurnal Integrasi, vol. 8, pp. 1-5, 2016.

[2] N. A. Z. Ruyung Hikayana Suki, "Implementasi RFID Sebagai Pengaman Pada Sepeda Motor untuk Mengurangi Tindak Pencurian," Jurnal Mahasiswa TEUB, vol. 2, no. 7, pp. 1-5, 2014.

[3] A. A. Satya, "Pemanfaatan E-Ktp Untuk Pengaktifan Sepeda Motor Berbasis Arduino UNO," Jurnal Transistor Elektro dan Informatika (TRANSISTOR EI), vol. 2, no. 1, pp. 15-20, 2017.

[4] d. E. R.R.Rachmat, "Pengaman Sepeda Motor Berbasis Mikrokontroler," JETri, vol. 13, no. 2, pp. 1-10, 2016.

[5] E. Saputro and H. Wibawanto, "Rancang Bangun Pengaman Pintu Otomatis Menggunakan E-KTP Berbasis Mikrokontroler Atmega328," Jurnal Teknik Elektro, vol. 8, no. ISSN 1411 - 0059, pp. 1-4, 2016.

[6] N. S. E. M. Dwi Yoga Hari Prasetya, "Rancang Bangun Sistem Keamanan Mobil Dengan Memanfaatkan RFID Pada E-KTP," Jurnal Teknik Elektro Universitas Brawijaya, vol. 3, no. 1, pp. 16, 2015.

[7] U. T. L. J. M. Riyanto Mustolih, "Utilization of EKTP as Home Safety Using Arduino Nano Based on Android," JOIN (Jurnal Online Informatika), vol. 4, no. 1, pp. 9-15, 2019.

[8] T. N. Pangaribuan, "Perancangan Alat Pengaman Kendaraan Bermotor Roda Dua Berbasis Mikrokontroler Atmega 8535 Menggunakan RFID," Saintia Fisika, pp. 1-8, 2013.

[9] T. W. Fahlepi Roma Doni, "Rancangan Pengaman Sepeda Motor Berbasis Mikrokontroler Atmega16 dengan Kontrol Android," Evolusi, vol. 3, no. 1, pp. 29-35, 2015.

[10] D. H. F. H. Y. Abdul Rahman, "Rancang Bangun Sistem Starter Kendaraan Bermotor Menggunakan Kartu RFID," in Seminar Nasional Teknologi Informasi dan Multimedia 2015, Yogyakarta, 2015. 